\title{
Transesterification of Waste Cooking Oil to Biodiesel over Calcined Hydroxy Sodalite (HS) Catalyst: A preliminary investigation
}

\author{
Chabisha P. Makgaba and Michael O. Daramola* \\ School of Chemical and Metallurgical Engineering, Faculty of Engineering and the Built Environment, University of the \\ Witwatersrand, Wits 2050, Johannesburg, South Africa \\ ${ }^{*}$ Corresponding author
}

\begin{abstract}
In this article, preliminary investigation on the use of hydroxy sodalite (HS) as a solid catalyst for the transesterification of waste cooking oil (WCO) to biodiesel is presented. Hydroxy sodalite was synthesized in our laboratory via the conventional hydrothermal synthesis technique and the crystals were used as basic solid catalyst to convert waste cooking oil to biodiesel. Physicochemical properties of the as-synthesized HS catalyst were obtained using Fourier Transform Infrared Spectroscopy (FT-IR) for surface chemistry and Scanning Electron Microscopy (SEM) for the morphology. The reaction was conducted at $60^{\circ} \mathrm{C}$ for $6 \mathrm{~h}$ at a methanol-to-WCO ratio of 7.5:1 using 3 wt. $\%$ HS catalyst. The stirring was at $400 \mathrm{rpm}$ to ensure uniform concentration and heat distribution during the reaction. The product obtained after the reaction was analyzed using a pre-calibrated Chromatography- Mass Spectrometer (GC-MS). The SEM images of the solid catalyst and the FTIR spectra show that HS particles were synthesized. The result of the analysis of the product revealed that biodiesel was produced. As far as could be ascertained, this is the first open report on the use of HS as solid catalyst for biodiesel production. The results of the investigation opened up further on-going research efforts in this area in our laboratory and subsequent results will be communicated in the future.
\end{abstract}

Keywords-hydroxy sodalite; catalyst; waste cooking oil; biodiesel component

\section{INTRODUCTION}

The Combustion of fossil fuels has an immense detrimental effect on the environment. The release of pollutant gases such as $\mathrm{NOx}, \mathrm{SOx}$, and $\mathrm{CO}$ is inevitable during this process. In addition, the price instability of fossil fuels poses a serious threat to countries with limited resources. Taking into account the limited amount of energy resources, their increasing prices and environmental issues associated with the use of conventional fuels for energy, other means of producing energy sustainably have become the forefront of research. Amongst the studies for other means of providing sustainable energy is biodiesel, which is a branch of biofuels and has become an essential alternative for liquid fuels.

Previous studies have demonstrated the use of typical edible plant oils, such as soybean, rapeseed oil and palm oil for the production of biodiesel [1]. These raw materials are not entirely suitable, more especially in developing countries, due to the limited supply and high cost associated with their application, as well as competition with the food chain [3]. Therefore, low cost, non-edible oils such as Jatropha oil, animal fat and waste cooking oil have been suggested and tested as alternatives [4-7]. However, the main disadvantage of these non-edible types of feedstock is the high content of free fatty acid (FFA) within the oils, which poses problems in the production process. Consequently, Biodiesel from high FFA content feedstock is conventionally produced by a two-stage process: esterification, followed by transesterification [8]. The esterification step serves to reduce the amount of FFAs present in the oil in order to allow for the transesterification reaction to commence [9]. The implication of this additional process unit is inevitably the additional costs associated with the biodiesel production.

In recent times, the use of heterogeneous catalysts has been proven to be very effective in converting high FFA feedstock directly to biodiesel, thereby by-passing the esterification stage $[4,7,10-11]$. The most commonly used heterogeneous catalysts for the production of biodiesel are ion-exchange resins, inorganic-oxide solid acids and supported noble-metal oxides. However, a dramatic decrease in the catalytic activity of these catalysts has been observed due to their absorption of water during biodiesel production [10].Besides the sharp reduction in the catalytic activity, the catalysts can form a slurry with the products by absorbing water and carbon dioxide, thereby increases the viscosity of the product mixture, making product separation very difficult [12]. In recent times, a few research efforts have been expended on the development of heterogeneous catalysts for biodiesel production [4,7,12-13]. For biodiesel production from WCO, recent concerted research efforts have investigated the use of solid-base catalysts obtained from pyrolyzed rice husk [10] and silica sulfuric acid [14]. As far as could be ascertained, there is no report in the open literature on the conversion of WCO to biodiesel over calcined solid hydroxy sodalite (HS) catalyst. As a contribution to the concerted research efforts in this area, this paper presents results of a preliminary investigation on the conversion of WCO to biodiesel over heterogeneous HS catalyst. 


\section{MATERIAL AND METHOD}

\section{A. Materials}

Waste cooking oil was obtained from a local restaurant in Braamfontein, Johannesburg, South Africa. The analytical grade methanol (99\%), isopropanol (99\%), ethanol(95\%), catalyst materials; anhydrous sodium metal silicate $\left(\mathrm{Na}_{2} \mathrm{SiO}_{3}\right)$, sodium hydroxide $(\mathrm{NaOH})$, anhydrous sodium aluminate $\left(\mathrm{NaAlO}_{2}\right)$ and all GC analytical standard chemicals; FAME (MIX, C4-C24, 100MG NEAT) and Glycerol( $99 \%$ ) were used in this study. All chemicals were purchased from SigmaAldrich, South Africa.

\section{B. Free Fatty Acid (FFA) Content and Characterization of Catalyst}

Free fatty acid content in WCO was determined to ensure that a considerable amount of free fatty acids exist in the WCO. This was done to confirm the need for a heterogeneous catalyst. It was also required to prove the tolerance of HS to a high content of free fatty acid in biodiesel production. Determination of the FFA content was carried out as described elsewhere [7] and the acid value of the WCO was calculated using Equation (1):

$$
\text { Actd value }=\frac{\text { Eve }}{\mathrm{m}}
$$

Where $\mathrm{K}$ is the acid value constant (a neutralization number) for cooking oil amounting to 56.1 (this is the mass of $\mathrm{KOH}$ in milligrams that is required to neutralize $1 \mathrm{~g}$ of chemical substance). The concentration of titrate solution is denoted as $\mathrm{C}$ in units of $(\mathrm{g} / \mathrm{ml})$. The volume of titrate required to neutralize the sample is denoted as $\mathrm{V}$ in units of $(\mathrm{mL})$. Lastly, the mass of sample used is denoted as $m$ in units of (g).

\section{Catalyst Preparation and Characterization}

Hydroxy sodalite particles were prepared from a mixture of the anhydrous Sodium meta silicate $\left(\mathrm{Na}_{2} \mathrm{SiO}_{3}\right)$, sodium hydroxide $(\mathrm{NaOH})$, anhydrous sodium aluminate $\left(\mathrm{NaAlO}_{2}\right)$ and de-ionized by hydrothermal synthesis method via hydrothermal synthesis described elsewhere [15]. The FT-IR was used to characterize the chemical functional groups of the catalyst, with a wave number range from 400 to $4000 \mathrm{~cm}^{-1}$. In order to carry out an SEM analysis, the hydroxy sodalite catalyst was initially coated with ultrathin gold/palladium alloy due to its nonconductive nature. The determination of surface topology and morphology of the catalyst was determined by SEM, performed on a Carl Zeiss, operating at an accelerated voltage of $5.00 \mathrm{kV}$.

\section{Biodiesel Production}

The procedure and some of the reaction parameters used for the transesterification reaction were adapted from the work done by Guo, Peng, Dai, \& Xio (2010). Hydroxy sodalite particles were first calcined at $200^{\circ} \mathrm{C}$ for 2 hours to increase the catalyst activity; by removing moisture and volatile matter that may block the pores of the catalyst surface. The transesterification reaction was carried out in a $250 \mathrm{ml}$ three necked round bottomed flask, batch reactor setup; equipped with a reflux condenser to prevent loss of methanol. The flask charged with relevant amount of waste cooking oil, methanol and HS particles was immersed in a thermostat controlled water bath placed on a hot plate magnetic stirrer. The reaction conditions were: reaction time $6 \mathrm{~h}$; reaction temperature $60{ }^{\circ} \mathrm{C}$; methanol-to-WCO ratio 7.5:1; catalyst weight percentage 3 wt. \%; stirrer intensity $400 \mathrm{rpm}$. After the completion of the reaction, the catalyst particles were recovered from the mixture by filtration through nylon filter paper $(0.45 \mu \mathrm{m}$ pore dimension). Separating funnel was used to separate the products and glycerol was drained from the bottom of the funnel while biodiesel was collected from the top. Analysis of the samples was performed using a pre-calibrated Gas Chromatograph equipped with a LECO GCxGC Thermal Modulator (GC-MS, model: Agilent 7890N).

\section{RESULTS AND DISCUSSION}

The SEM image and the FTIR spectrum of the HS particles are presented in Figure I (a) Figure I (b), respectively. The EDX analysis of the HS crystals showed that $\mathrm{Si} / \mathrm{Al}=1-1.5$, indicating HS framework. The SEM image (Figure 1(a)) shows that HS crystals were successfully synthesized. However, a mixture of HS particles with cubic shape and nanorod-like shape were also observed. The observed morphology is consistent with previous studies where other shapes of hydroxy sodalite such as nanorods, flower-like, urchin, thread-ball and cubic/octahedral shape have been reported [16-17]. The FTIR spectrum in Figure I (b) shows the asymmetric stretching vibration of T-O-T (T-Si, Al) at $\sim 1000$ $\mathrm{cm}^{-1}$. In addition, the peaks around $740 \mathrm{~cm}^{-1}$ and $660 \mathrm{~cm}^{-1}$ can be assigned to the symmetric stretching vibration of T-O-T. The presence of water molecules in the framework of the synthesized HS is vividly shown with the strong broad band centered at $\sim 3600 \mathrm{~cm}^{-1}$ [18]. This information confirms the synthesis of pure HS particles and is in agreement with literature [19].
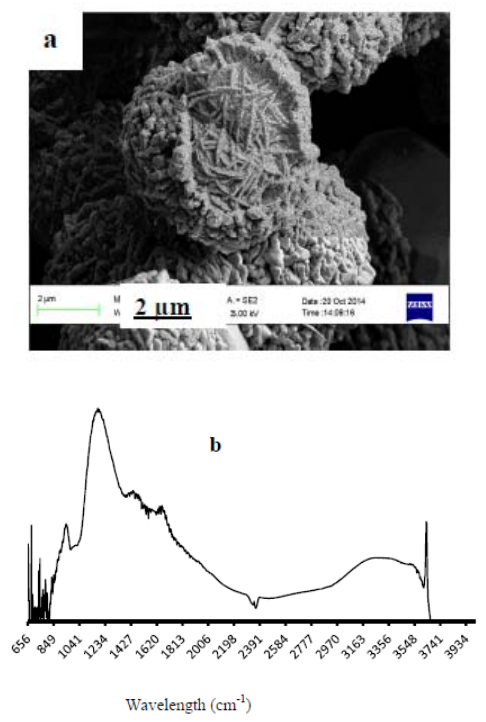

FIGURE I. PHYSICO-CHEMICAL CHARACTERIZATION OF THE HS CATALYST. SEM IMAGES (A); FTIR SPPECTRUM (B). 
The free fatty acid content in the WCO sample was determined to be $3.28 \%$. According to previous studies, the base-catalyzed trans-esterification requires that oil samples should have FFA content less than $1 \%$ to avoid the occurrence of hydrolysis and saponification reactions [20]. The production of biodiesel was successful even though the FFA content exceeded the recommended $1 \%$ because of the use of hydroxy sodalite as a catalyst for trans-esterification. Since the structure of HS is made up of Si-O-Si, it could be speculated that it exhibits the same behavior as sodium metasilicate whereby hydrolysis reaction with sodium silicate and water resulted in the formation of $\mathrm{NaOH}$ and $\mathrm{Si}-\mathrm{O}-\mathrm{H}$ [4], thereby suppressing the formation of soap because of the decreased water content (less than 4\%) [12].The tolerance of HS to water could be attributed partly to its porous structure. Furthermore, the unique structure of the catalyst could enhance sequential hydration to occur in three steps when there are high amounts of water present. In addition, the $\mathrm{Si}-\mathrm{O}-\mathrm{Si}$ bridges that form the cages of the HS could hydrolyze and cause $\mathrm{H}_{4} \mathrm{SiO}_{2}$ monomers to be released and thus produce $-\mathrm{OH}$ which prevents soap formation [12].

Since biodiesel mixture comprises major components of fatty acid methyl esters of long chain carbon chains (C6:0C24:1) was used as the standard. Qualitatively, the results of the GC-MS analysis of the reaction products are shown in Figure II (top \& bottom) and Table I (for the biodiesel standard) and Table II (for the produced biodiesel). From the peaks depicted by Figure 2, FAME components in the mixtures for both the standard and produced biodiesel could be identified and compared. FAME peaks are only identified between 13 minutes and 19 minutes retention times for the produced biodiesel when compared to peaks in the standard. This can be attributed to the fact that the FAME components in the biodiesel largely depend on the type of feedstock used. However, major components making up biodiesel mixture are common in the two mixtures; confirming the feasibility of using the synthesized HS as a catalyst for the transesterification reaction of WCO to biodiesel.

\section{CONCLUSION}

The results of the preliminary investigation reveal the possibility of converting WCO to biodiesel over calcined HS catalyst. Although information about the conversion and the biodiesel yield with this catalyst is not provided in this article. However, the information contained in this piece serves as impetus for further research efforts on the use of HS as solid catalyst for biodiesel production. At the moment, research efforts are geared towards an in-depth understanding of the mechanism and kinetics of the HS catalyzed transesterification process for biodiesel production in our laboratory. Results of our findings will be communicated in the future.

\section{ACKNOWLEDGMENT}

The authors are grateful to the National Research Foundation (NRF), South Africa for the bursary provided
PCM for the MSc degree programme at the University of the Witwatersrand.

\section{REFERENCES}

[1] F.Guo and Z. Fang, "Biodiesel Production with Solid Catalysts, Biodiesel - Feedstocks and Processing Technologies,'In M. Stoytcheva and G. Montero , Eds. Rijeka: InTech, 2011, p. 339.

[2] O.J. Alamu, M.A.Waheed and S.O. Jekayinfa, "Effect of ethanol-palm kernel oil ratio on alkali-catalyzed biodiesel yield", Fuel, vol. 87, 2008, pp. 1529-1533.

[3] J. Gerpen, G. Knothe and J. Krahl, " Biodiesel production - biodiesel handbook," Champaign: AOCS PRESS, 2005.

[4] F.Guo, N. Wei,Z. Xui and Z. Fang, "Transesterification mechanism of soybean oil to biodiesel catalyzed by calcined sodium silicate," Fuel, vol. 93, pp. 468-472.

[5] E.F. Aransiola, M.O. Daramola, V.T. Ojumu, S.K. Layokun, B.O. Solomon, "Homogeneously catalyzed transesterification of Nigerian Jatropha curcas oils to Biodiesel: a kinetic study," MRC, vol. 2, 2013, pp. 83-89.

[6] E.F. Aransiola, M.O. Daramola, V.T. Ojumu, S.K. Layokun, B.O Solomon ," Nigerian Jatropha curcas oil seeds: prospect for biodiesel production in Nigeria,” IJRER, vol.2 ,2012, pp. 317-325.

[7] M.O. Daramola, D. Nkazi, K. Mtshali, "Synthesis and evaluation of catalytic activity of calcined sodium silicate for transesterification of waste cooking oil to biodiesel," IJRER, vol.5, 2015, pp.517-523.

[8] Z. Yaakob, M. Mohammad, M. Alherbawi, Z. Alam, and K.Sopian, "Overview of the production of biodiesel from waste cooking oil," Renew. Sustainable Energy Rev., vol. 18, 2013, pp.184-193.

[9] Y. Sharma, B. Singh and J. Korstad, "(2011). Advancements in solid acid catalysts for ecofriendly and economically viable synthesis of biodiesel. Biofuels,vol. 5, 2011, pp. 69-92.

[10] M. Li, Y. Zheng, Y. Chen and X. Zhu, "Biodiesel production from waste cooking oil using heterogeneous catalyst from pyrolyzed rice husk," Bioresour. Technol. ,vol. 154, 2014, pp. 345-348.

[11] A.Gnanaprakasam,V.Sivakumar, A. Surendhar, M. Thirumarimurugan and T. Kannadasan, "Recent strategy of biodiesel production from waste cooking oil and process influencing parameters," Energy, 2013, pp. 1-8.

[12] F.Guo , Z. Peng, J. Dai and Z. Xui, "Calcined sodium silicate as solid base catalyst for biodiesel production," Fuel Processing Technology, ,2010, vol. 91, pp. 322-328.

[13] A. Talebian-Kiakalaieh, N.A.S. Amin, A. Zarei and H. Jaliliannosrati, "Biodiesel production from high free fatty acid waste cooking oil by solid acid catalyst," In: proceedings of the $6^{\text {th }}$ International Conference on Process Systems Engineering, 2013, pp. 572-576.

[14] K.A. Shah, J.K. Parikh and K.C. Maheria, "Optimization studies and chemical kinetics of silica sulfuric acid-catalysed biodiesel synthesis from waste cooking oi," Bioenergy Resources, vol. 7, 2014, pp. 206-216.

[15] M.O. Daramola, A. Dinatand S. Hasrood, "Synthesis and characterization of nanocomposite ceramic/hydroxy sodalite membrane via pore-plugging technique," J. Memb. Separ. Tech, vol. 4 pp. 1-7.

[16] B. Bayati, A.A Babaluo and R. Karimi, (2008) J. Eur. Ceram. Soc, vol. 28, 2008,pp. 2653-2657.

[17] M.K Naskar,D Kundu and M. Chatterjee, "Effect of process parameters on surfactant-based synthesis of hydroxy sodalite particles, " Mater. Lett., vol.65,2011, pp.436-438.

[18] D.W. Breck ,"Zeolite molecular sieves: structure, chemistry and use," USA, New York: Wiley, 1974.

[19] J.C. Buhl, K. Schuster and L. Robben, "Nanocrystalline sodalite grown from superalkaline $\mathrm{NaCl}$ bearing gels at low temperature $(333 \mathrm{~K})$ and the influence of TEA on crystalization process“, Micropor. Mesopor. Mater., vol. 142, 2011, pp. 666-671.

[20] M. Mathiyazhagan and A. Ganapathi, " Factors affecting biodiesel production,” Research in Plant Biology, vol.1 , 2011, pp. 01-05. 

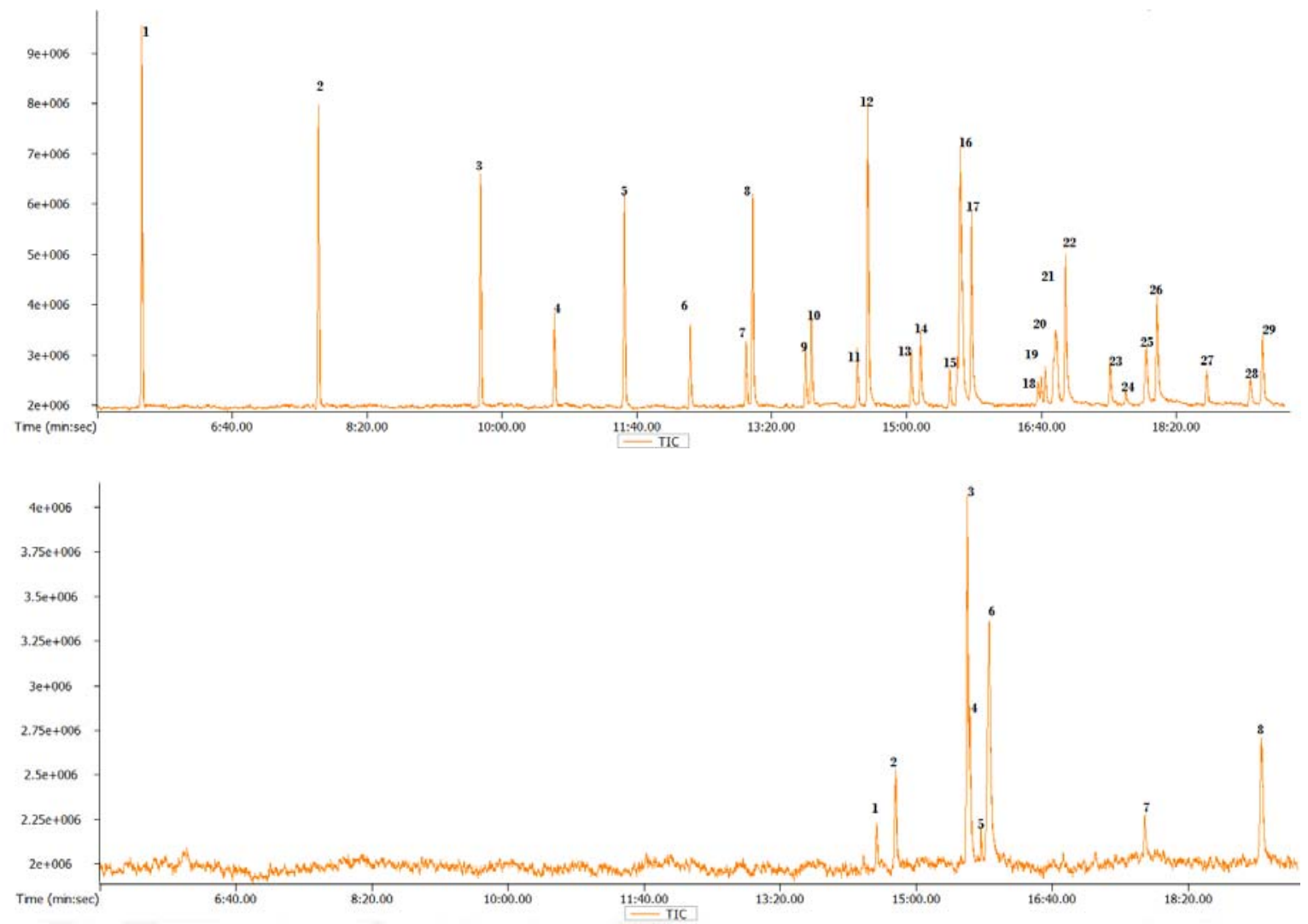

FIGURE II. CHROMATOGRAMS OF THE BIODIESEL SAMPLES. OBTAINED FROM THE STANDARD BIODIESEL (TOP); OBTAINED FROM THE TRANSESTERIFICATION OF WCO OVER HS CATALYST (BOTTOM).

TABLE I. GC-MS ANALYSIS OF THE BIODIESEL STANDARD

\begin{tabular}{|c|c|c|c|c|c|c|c|}
\hline $\begin{array}{c}\text { Peak } \\
\text { no. }\end{array}$ & Name & & $\begin{array}{c}\mathrm{RT} \\
\text { (min:sec) }\end{array}$ & $\begin{array}{c}\text { Peak } \\
\text { no. }\end{array}$ & Name & & $\begin{array}{c}\text { RT } \\
\text { (min:sec) }\end{array}$ \\
\hline 1 & Hexanoic acid, methyl ester & C6:0 & $05: 33$ & 16 & Linoleic acid, methyl ester & $\mathrm{C} 18: 2$ & $15: 37$ \\
\hline 2 & Octanoic acid, methyl ester & $\mathrm{C} 8: 0$ & $07: 44$ & 17 & Oleic acid, methyl ester & $\mathrm{C} 18: 1$ & $15: 39$ \\
\hline 3 & Decanoic acid, methyl ester & $\mathrm{C} 10: 0$ & $09: 44$ & 18 & Linolenic acid, methyl ester & C18:2 & $15: 40$ \\
\hline 4 & $\begin{array}{c}\text { Tridecanoic acid, methyl } \\
\text { ester }\end{array}$ & $\mathrm{C} 13: 0$ & $10: 39$ & 19 & Octadecanoic acid, methyl ester & C18:0 & $15: 48$ \\
\hline 5 & $\begin{array}{c}\text { Dodecanoic acid, methyl } \\
\text { ester }\end{array}$ & $\mathrm{C} 12: 0$ & $11: 30$ & 20 & Arachidonic acid & $\mathrm{C} 20: 4 \mathrm{n} 6$ & $16: 37$ \\
\hline 6 & $\begin{array}{c}\text { Tridecanoic acid, methyl } \\
\text { ester }\end{array}$ & $\mathrm{C} 13: 0$ & $12: 19$ & 21 & $\begin{array}{c}\text { 5,11,14,17-Eicosapentaenoic } \\
\text { acid, methyl ester(all-Z) }\end{array}$ & - & $16: 39$ \\
\hline 7 & $\begin{array}{c}\text { Tetradecanoic acid, methyl } \\
\text { ester }\end{array}$ & $\mathrm{C} 14: 0$ & $13: 01$ & 22 & Linolenic acid, methyl ester & $\mathrm{C} 18: 2$ & $16: 43$ \\
\hline 8 & Methyl tetradecanoic acid & $\mathrm{C} 14: 0$ & $13: 06$ & 23 & $\begin{array}{c}\text { 11,14-Eicosadienoic acid, } \\
\text { methyl ester, }(Z, Z, Z)\end{array}$ & - & $16: 48$ \\
\hline 9 & Oleic acid, methyl ester & $\mathrm{C} 18: 0$ & $13: 45$ & 24 & Oleic acid, methyl ester & C18:0 & $16: 50$ \\
\hline 10 & $\begin{array}{c}\text { Tridecanoic acid, methyl } \\
\text { ester }\end{array}$ & $\mathrm{C} 13: 0$ & $13: 49$ & 25 & Linolenic acid, methyl ester & $\mathrm{C} 18: 2$ & $16: 51$ \\
\hline 11 & $\begin{array}{c}\text { Hexadecanoic acid, methyl } \\
\text { ester(Z) }\end{array}$ & $\mathrm{C} 16: 0$ & $14: 23$ & 26 & Eicosanoic acid, methyl ester & $\mathrm{C} 20: 0$ & $16: 57$ \\
\hline 12 & $\begin{array}{c}\text { Hexadecanoic acid, methyl } \\
\text { ester }\end{array}$ & $\mathrm{C} 16: 1$ & $14: 31$ & 27 & Hexadecanoic acid, methyl ester & C16:1 & $17: 31$ \\
\hline 13 & $\begin{array}{l}\text { Cyclopropaneoctanoic acid, } \\
\text { methyl ester }\end{array}$ & $\mathrm{C} 17: 1$ & $15: 03$ & 28 & Oleic acid, methyl ester & C18:0 & 19:15 \\
\hline 14 & $\begin{array}{c}\text { Tridecanoic acid, methyl } \\
\text { ester }\end{array}$ & $\mathrm{C} 13: 0$ & $15: 11$ & 29 & $\begin{array}{l}\text { Hexadecanoic acid, 15-methyl-, } \\
\text { methyl ester }\end{array}$ & - & 19:24 \\
\hline 15 & $\begin{array}{l}\text { ç-Linolenic acid, methyl } \\
\text { ester }\end{array}$ & $\mathrm{C} 18: 2$ & $15: 32$ & & & & \\
\hline
\end{tabular}


TABLE II. GC-MS ANALYSIS OF THE PRODUCED BIODIESEL

\begin{tabular}{|c|l|c|c|}
\hline $\begin{array}{c}\text { Peak } \\
\text { no. }\end{array}$ & \multicolumn{1}{|c|}{ Name } & RT(min:sec) \\
\hline 1 & Tridecanoic acid, methyl ester & C13:0 & $14: 31$ \\
\hline 2 & Undecanoic acid, methyl ester & C11:0 & $14: 45$ \\
\hline 3 & Linoleic acid, methyl ester & C18:2 & $15: 37$ \\
\hline 4 & Oleic acid, methyl ester & C18:1 & $15: 48$ \\
\hline 5 & Octadecanoic acid, methyl ester & C14:0 & $15: 54$ \\
\hline 6 & 9,12 Octadecanoic acid & C18:2 & $17: 48$ \\
\hline 7 & 10 -Undecyn-1-ol & & $19: 14$ \\
\hline 8 & 9,12 Octadecadienoyl chloride & & - \\
\hline
\end{tabular}

